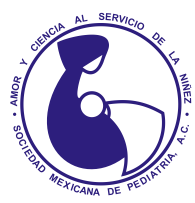

\title{
A un año de la pandemia, ¿qué hemos aprendido?
}

\author{
One year after the pandemic, what have we learned? \\ Roberto Guillermo Calva-y-Rodríguez,* Alicia Robledo-Galván,* Alfredo Vigueras-Rendón,* \\ Guillermo Yanowsky-Reyes,* Francisco Paredes-Fernández,* Manuel Gil-Vargas* \\ * Academia Mexicana de Pediatría. Mesa Directiva 2019-2021. México.
}

Hace más de un año las autoridades sanitarias de China informaban del brote de una epidemia de casos nuevos de neumonía en una región de Wuhan, la extensa capital de la provincia Hubei, en China central. El 30 de enero de 2020, la Organización Mundial de la Salud (OMS) declaró a la enfermedad denominada COVID-19 ("corona", "virus" y disease [enfermedad en inglés], mientras que 19 representa el año en que surgió) como emergencia de salud pública de importancia internacional (ESPII); debido al avance de la enfermedad en diversas partes del mundo, el 11 de marzo del mismo año, el Dr. Tedros Adhanom Ghebreyesus (Director de la OMS) la declaró como pandemia.

A un año de este suceso sanitario, se estima que 72 millones de personas han sido infectadas en todo el mundo, y que han fallecido 1,600,000 personas, lo cual corresponde a una letalidad de $2.4 \%$ en una pandemia que aún no se ha controlado.

Con relación al virus se reconoce que es muy contagioso mediante gotículas de saliva, fundamentalmente. Además, a lo largo de la pandemia el virus ha mutado, por lo que las variantes del virus es un tema de preocupación actual, como la mutación de la proteína Spike de un ácido aspártico por una glicina (de D614 a G614).

Para que el virus penetre en nuestro organismo tienen que existir receptores ACE2, estos receptores se encuentran en los tejidos respiratorios, pero también en el digestivo y en todos los órganos, lo que se convierte en la puerta de entrada del virus. La transmisión ocurre con mayor frecuencia en lugares cerrados, por contacto de personas cercanas y cuando no se realizan las medidas de protección: lavado de manos, distanciamiento físico, uso de cubrebocas y protección facial.

En cuanto al cuadro clínico, aunque la mayor parte de las personas cursan asintomáticas, el 87\% presenta alguna sintomatología; la gravedad depende de diversos factores, como ser mayor a 60 años, tener obesidad, diabetes o hipertensión. Los casos graves presentan principalmente sintomatología respiratoria, pero SARS-CoV-2 puede afectar a todos los órganos. Hasta $40 \%$ puede tener manifestaciones cardiovasculares como insuficiencia cardiaca, cardiomiopatía, miocarditis, infarto de miocardio, arritmias, además de eventos trombóticos arteriales y venosos hasta en 16\%. En sistema nervioso causa cefalea, encefalitis, meningitis, mialgias, síndrome de Guillain-Barré, así como pérdida del gusto y olfato hasta en $64 \%$ de los casos, los cuales pueden prolongarse por más de seis meses. Asimismo, se ha descrito hepatitis, dolor abdominal (especialmente en los niños), insuficiencia renal aguda, tiroiditis subaguda, insuficiencia adrenal y conjuntivitis. En piel se ha detectado microtrombosis, eritema y ulceraciones. A diferencia de los pacientes adultos, en los niños el cuadro clínico es mucho más benigno y, por fortuna, sólo unos pocos casos llegan a ser graves. Sin embargo, dado que tienen pocos síntomas, se considera que los niños son un vehículo para el contagio de adultos.

Correspondencia: Roberto Guillermo Calva-y-Rodríguez, dr.robertocalvarodriguez@gmail.com

Citar como: Calva-y-Rodríguez RG, Robledo-Galván A, Vigueras-Rendón A, Yanowsky-Reyes G, Paredes-Fernández F, Gil-Vargas M. A un año de la pandemia, ¿qué hemos aprendido? Rev Mex Pediatr. 2021; 88(1): 3-4. https://dx.doi.org/10.35366/99411 
Una vez concluido el cuadro agudo, un grupo importante de pacientes tiene secuelas, lo cual se ha denominado como síndrome post-COVID-19, teniendo como manifestaciones principales a fatiga crónica, dolor articular, dolor precordial y pérdida de la memoria. Se estima que una tercera parte tiene disnea y cansancio durante seis meses.

En la actualidad, para el diagnóstico, los estudios de laboratorio que confirman la enfermedad son: 1) PCR molecular (rRT-PCR), el cual detecta el material genético del virus o sus fracciones. Esta técnica se considera el estándar de oro o el mejor método, pero su costo es elevado y puede demorar 48 horas para obtener resultados. 2) Determinación de antígeno (PDR-Ag), que se basa en la detección de proteínas del virus (Spike), o bien su réplica en el tejido. En comparación a rRT-PCR el resultado se obtiene en aproximadamente 90 minutos, pero su sensibilidad es del $97 \%$ y especificidad del $99 \%$, por lo que siempre deberá confirmar la enfermedad por rRT-PCR. 3) Determinación de anticuerpos IgM e IgG, la cual no debe ser utilizada para establecer el diagnóstico de COVID-19, ya que solamente sirve para determinar si existe respuesta inmune a una posible infección actual o previa; hay diferentes maneras de cuantificarla, pero puede ser desde una prueba rápida (20 minutos para dar resultados), la cual tiene sensibilidad del $87.5 \%$ y especificidad del $98.5 \%$.

En cuanto al tratamiento, a pesar de múltiples estudios realizados en todo el mundo, en el momento actual no existe alguno que haya demostrado eficacia clínica específica contra SARS-CoV-2. A partir de la investigación y experiencias con antivirales, anticoagulantes, antiinflamatorios, antimicrobianos, vitaminas, minerales, oligoelementos, ácidos grasos e inmunomoduladores, podemos sintetizar los resultados en seis grupos: 1) altamente efectivo para pacientes graves: dexametasona, hidrocortisona y metilprednisolona. 2) En estudio: baricitinib, 6-CSF, telmisartán. 3) Sin efecto: famotidina, vitamina $\mathrm{D}$, melatonina, molnupiravir, aviptadil, favipiravir/avifavir, umifenovir/arbidol, ribavirina/ virazide, ivermectina, sildenafil, colchicina, enoxaparina, heparina, casirivimab/imdevimab, células madre. 4) Con resultados no satisfactorios o contradictorios: remdesivir, zinc, interferón alfa $2 \mathrm{~b}$, interferón beta $1 \mathrm{a}$, tocilizumab, sarilumab, anakinra, plasma de pacientes convalecientes. 5) No se debe utilizar: azitromicina, lopinavir/ritonavir, hidroxicloroquina/cloroquina. 6) Sin datos en humanos y ciencia no lo avala: dióxido de cloro.

En este punto, es necesario señalar que con muy contadas excepciones (como el síndrome inflamatorio multisistémico pediátrico) estos fármacos no se han probado en niños.

En contraste con el tratamiento, por fortuna, la vacunación inició en diciembre de 2020, la cual ha llegado para ser un coadyuvante en el combate a la enfermedad. Las vacunas disponibles han demostrado ser eficaces y seguras a manera individual; sin embargo, se requiere aún mucho esfuerzo en todo el mundo para lograr el control de la enfermedad. Por ejemplo, se ha calculado en modelos matemáticos que para que una vacuna sea efectiva a nivel poblacional, tiene que haber al menos el $60 \%$ de personas vacunadas. Por lo anterior, si habitan 7,700 millones de personas en el mundo, habría que vacunar a 6,620 millones para lograr tal efectividad. Las perspectivas actuales plantean que será posible vacunar de 130 a 700 millones, por lo cual sólo se estará protegiendo de tres a $15 \%$ de la población, por lo tanto, la solución a corto o mediano plazo no será posible.

Existe una teoría que, para el control de la pandemia de COVID-19, la utilización de cubrebocas o mascarillas faciales puede ser una buena estrategia universal. Se propone que quienes los utilizan con regularidad y se infectan, serían casos leves o asintomáticos, lo cual puede ser una forma de "variolización" que generaría inmunidad y, por lo tanto, ralentizaría la propagación del virus.

Por todo lo anterior, hoy en día la única forma efectiva de evitar el incremento de los efectos devastadores de COVID-19 es mantener las acciones para reducir la transmisión. De ahí que los trabajadores de la salud deberemos continuar promoviendo las siguientes medidas sanitarias:

1. Lavarse las manos con agua y jabón al menos por 20 segundos, varias veces al día.

2. Mantener una distancia adecuada (al menos dos metros) entre las personas.

3. Uso de cubrebocas correctamente colocado, de la barbilla al puente nasal.

4. No tocarse la cara, ojos y nariz con las manos.

5. Evitar mantenerse en lugares cerrados y mantener ventilados los sitios que habitamos.

6. No asistir a reuniones en las que existan más de 10 personas.

Finalmente, debemos reconocer que, a un año de la pandemia, la enfermedad por SARS-CoV-2 nos ha enseñado más de lo que sabíamos antes.

Conflicto de intereses: Los autores declaran que no tienen. 